\title{
Hardware in the loop co-simulation of finite set-model predictive control using FPGA for a three level CHB inverter
}

\author{
Mai Van Chung ${ }^{1}$, Do Tuan $\mathrm{Anh}^{2}$, Phuong Vư ${ }^{3}$, Manh Linh Nguyen ${ }^{4}$ \\ 1,2,3,4 School of Electrical Engineering, Hanoi university of science and technology, No.1, Dai Co Viet, Hai Ba Trung, \\ Ha Noi, Viet Nam \\ ${ }^{1}$ Hung Vuong University, Nguyen Tat Thanh, Nong Trang, Viet Tri, Phu Tho, Viet Nam
}

\begin{tabular}{l} 
Article Info \\
Article history: \\
Received Feb 9, 2020 \\
Revised May 26, 2020 \\
Accepted Jun 20, 2020 \\
\hline Keywords: \\
Cascaded H-bridge inveter \\
FPGA \\
Hardware in the loop \\
Induction motor control \\
Predictive current control
\end{tabular}

Article Info

rticle history:

Received Feb 9, 2020

Revised May 26, 2020

Keywords:

Cascaded H-bridge inveter

Hardware in the loop

Predictive current control

\begin{abstract}
Along with the development of powerful microprocessors and microcontrollers, the applications of the model predictive controller, which requires high computational cost, to fast dynamical systems such as power converters and electric drives have become a tendency recently. In this paper, two solutions are offered to quickly develop the finite set predictive current control for induction motor fed by 3-level H-Bridge cascaded inverter. First, the field programmable gate array (FPGA) with capability of parallel computation is employed to minimize the computational time. Second, the hardware in the loop (HIL) co-simulation is used to quickly verify the developed control algorithm without burden of time on hardware design since the motor and the power switches are emulated on a real-time platform with high-fidelity mathematical models. The implementation procedure and HIL co-simulation results of the developed control algorithm shows the effectiveness of the proposed solution.
\end{abstract}

This is an open access article under the CC BY-SA license.



\section{Corresponding Author:}

Manh Linh Nguyen, Phuong Vu School of Electrical Engineering Hanoi University of Science and Technology

No.1, Dai Co Viet Road, Hai Ba Trung, Hanoi, Viet Nam

Email: linh.nguyenmanh@hust.edu.vn,phuong.vuhoang@hust.edu.vn

\section{INTRODUCTION}

Nowadays, most commercial inverters for AC machines are installed with field-oriented-control (FOC). To further improve the dynamic response of the FOC, new control strategies have been studied for the current control loop such as synchronous vector control, state feedback control, deadbeat control, neural network and fuzzy control [1]. Among them, model predictive control (MPC) has been considered as a powerful alternative control method for power converters and electrical drives [2-8]. The MPC, which was early developed in the 1960s, is an application of the optimal control theory [2], in which the system model is used to predict the future behavior of the system states in a predefined time horizon and then obtain the optimal control action which minimizes a given cost function. Despite of advantages such as intuitive concept, quick dynamic response, ability to handle constrained linear and nonliner multivariable dynamic systems [3], the application of MPC is restricted in the field of process control due to its relatively high computational cost. In recent years, with the development of of high-speed microcontroller and FPGA, the high computational cost problem of the MPC can be solved following that the application of the MPC has been expanded to fast dynamical systems such as power electronic converters and electrical drives. Due to the fact that the power electronic converters only have finite switching states, finite control set model predictive control (FCS-MPC) has been developed to select the switching state for the converters directly 
instead of using a modulator which is also complicated, especially in multi level inverters. The FCS-MPC has been successfully applied to the current control in three-phase inverters [9-14], matrix converter [15]. And induction machine [16-18]. An improved FCS-MPC is also proposed to solve the variable switching problem ininduction motor (IM) fed by 2-level voltage source inverter (VSI) [19].

Multilevel converters is widely used for medium-voltage (HV) and high power applications due to its remarkable advantages over the conventional two-level VSI such as: lower voltage stress, lower rate of voltage change (dv/dt), reduced total harmonic distortion (THD) and lower switching frequency which results in improved switching loss $[9,20]$. Among the multilevel inverter topologies, the CHB is the most successful configuration and already commercialized because of its modularity [21-23]. Typically, a motor control system consists of a conventional controller such as proportional-integral-differential (PID), state feedback, etc., and a pulse width modulation (PWM). For multilevel inverters, the higher the level, the more complex the PWM algorithm is, especially when other inherent problems of the multilevel topologies such as capacitor voltage balance, fault tolerant ability are considered. Hence, this research focuses on the application of FCS-MPC to IM fed by multilevel cascaded H-bridge (CHB) inverters. Instead of using the conventional $\mathrm{PWM}$, the voltage vector which minimizes the predictive current tracking error is selected directly in every consecutive sampling cycle. Without PWM algorithm and by using FPGA [24-26] as the controller, the FCSMPC algorithm can easily be sovle in very short time following that the response of the inner current is significantly improved in comparison with the conventional PID controller. Besides, multiple objectives can also be achieved by appropriately choosing the cost function. To avoid wasting time on hardware design and the risky experiments with high power systems, HIL platform manufactured by Typhoon is employed to quickly verify the developed control algorithm. By using the Typhoon HIL, the behavior of the motor and the CHB inverter are precisely evaluated in real-time by high-fidelity mathematical models. Realtime simulations with various scenarios are conducted and the results show that the employed FCS-MPC applied to CHB-fed IM drive can achieve good performance not only in terms of tracking accuracy but also dynamic response.

\section{SYSTEM DESCRIPTION}

\subsection{Overview of CHB inverter}

The typical configuration of a three-phase multilevel $\mathrm{CHB}$ is shown in Figure 1 (a). The fundamental component of the $\mathrm{CHB}$ is a single-phase H-brigde inverter which is normally called a power cell. Each phase of the CHB consists of several cells connected in series.

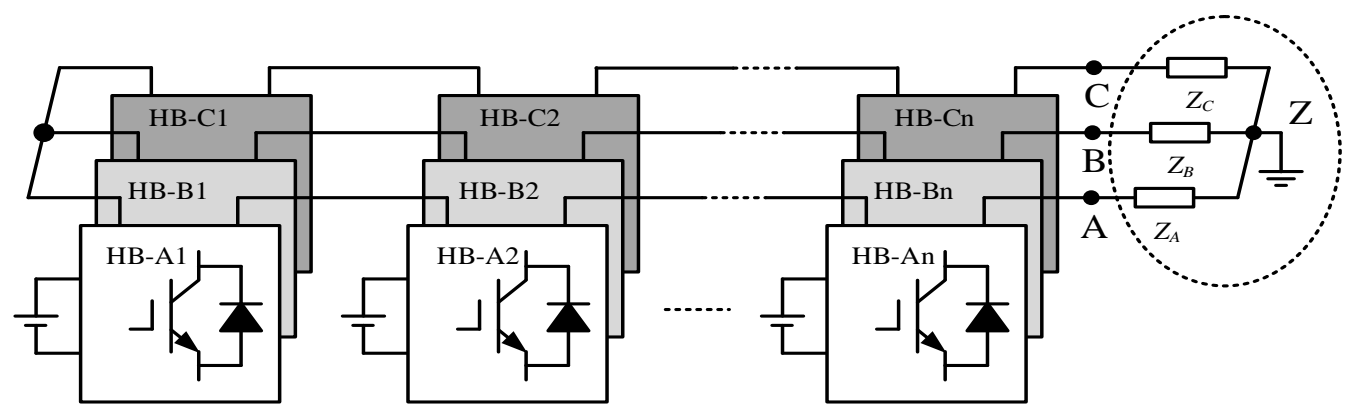

(a)

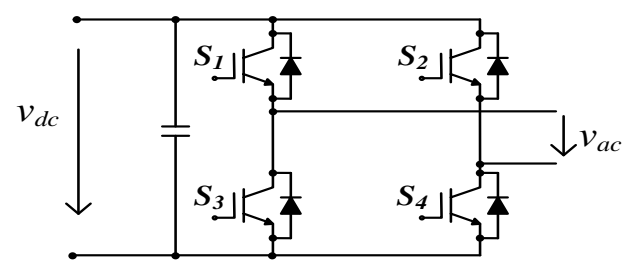

(b)

Figure 1. (a) Structure of a CHB inverter; (b) Topology of a cell

Assume that each phase consists of $n$ cells connected in series and each cell is fed with an independent dc voltage source $\mathrm{V}_{\mathrm{dc}}$. The power switches $\mathrm{S}_{1}-\mathrm{S}_{4}$ in cell $i$ of a phase can be controlled to generate 
three voltage levels $\left\{+\mathrm{V}_{\mathrm{dc}}, 0,-\mathrm{V}_{\mathrm{dc}}\right\}$ corresponding to cell state $S_{x i}=\{1,0,-1\}$ where $x$ represents phase $a, b$ or $c$. The voltage level of a phase is defined as the sum of all cell states in that phase as following:

$$
S_{x}=\sum_{i=0}^{n} S_{x i}
$$

The number of possible voltage levels for one phase is:

$$
m=2 n+1
$$

The output voltage of each phase is calculated by

$$
v_{A N}=V_{d c} \sum_{i=0}^{n} S_{a i} ; v_{B N}=V_{d c} \sum_{i=0}^{n} S_{b i} ; v_{C N}=V_{d c} \sum_{i=0}^{n} S_{c i}
$$

\subsection{Space voltage vector of 3 -level $\mathrm{CHB}$ inverter}

A voltage vector is formed by a combination of switching states. The total combinations of the CHB inverter is as follow:

$$
\begin{aligned}
& K_{m}=(2 n+1)^{3} \\
& K_{v}=12 n^{2}+6 n+1
\end{aligned}
$$

In multilevel $\mathrm{CHB}$ converters, same voltage vector can be implemented by several combination of switching states. Hence, the number of voltage vectors are normally less than the total switching states as following [9]. In this research, a three phase three level CHB inverter is used with 27 possible voltage vectors in static $\alpha \beta$ coordinate. By eliminating the switching states which generate high common-mode voltage, the number of employed voltage vectors are reduced to 19 as shown in Figure 2. These voltage vetor are employed in the FCS-MPC in the next section.

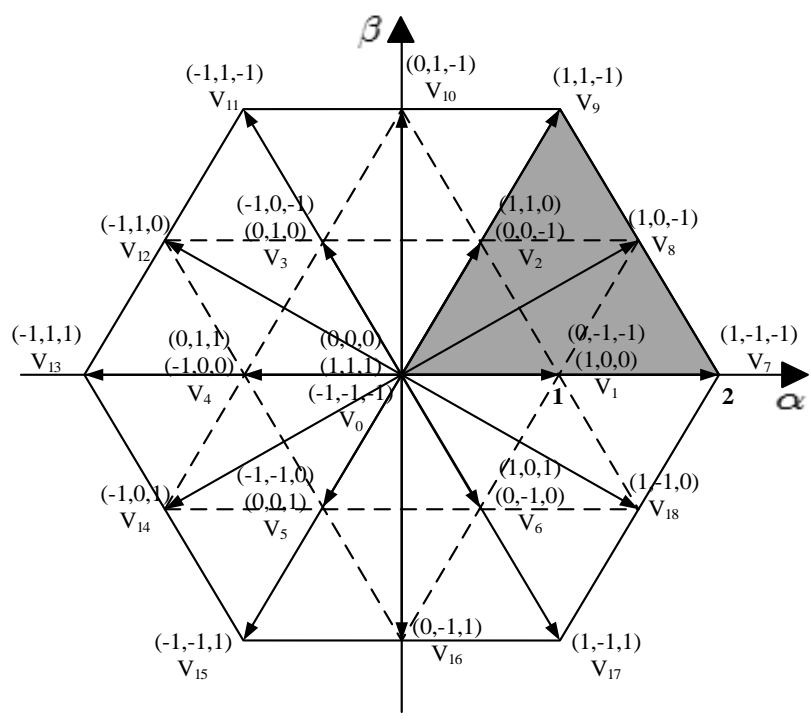

Figure 2. Space voltage vector of a 3-level CHB inverter

\subsection{Modeling of the induction motor}

In stationary frame $\alpha \beta$, the behavior of the IM can be represented by the following equations:

$$
\mathbf{u}_{s}^{s}=R_{s} i_{s}^{s}+\frac{d \boldsymbol{\Psi}_{s}^{s}}{d t} ; 0=R_{r} i_{r}^{s}+\frac{d \boldsymbol{\Psi}_{r}^{s}}{d t}-j z_{p} \omega \boldsymbol{\Psi}_{r}^{s}
$$


$\boldsymbol{\Psi}_{s}^{s}=L_{s} \boldsymbol{i}_{s}^{s}+L_{m} \boldsymbol{i}_{r}^{s} ; \boldsymbol{\Psi}_{r}^{s}=L_{m} \boldsymbol{i}_{s}^{s}+L_{r} \boldsymbol{i}_{r}^{s}$

In which $R_{s}, L_{s} R_{r}, L_{r}$ are resistance and inductance of the stator and rotor, respectively.

The current and flux of the stator and rotor are expressed in vector form as follow:

$\boldsymbol{u}_{s}^{s}=\left[\begin{array}{ll}u_{s \alpha} & u_{s \beta}\end{array}\right]^{T} ; \boldsymbol{i}_{s}^{s}=\left[\begin{array}{ll}i_{s \alpha} & i_{s \beta}\end{array}\right]^{T} ; \boldsymbol{i}_{r}^{s}=\left[\begin{array}{ll}i_{r \alpha} & i_{r \beta}\end{array}\right]^{T} ; \Psi_{s}^{s}=\left[\begin{array}{ll}\Psi_{s \alpha} & \Psi_{s \beta}\end{array}\right]^{T} ; \Psi_{r}^{s}=\left[\begin{array}{ll}\Psi_{r \alpha} & \Psi_{r \beta}\end{array}\right]^{T}$

Defining new variables as:

$\Psi_{r m}^{s}=\frac{1}{L_{m}} \Psi_{r}^{s} ; T_{r}=\frac{L_{r}}{C_{r}}, T_{s}=\frac{L_{s}}{R_{s}} ; \delta=1-\frac{L_{m}^{2}}{L_{s} L_{r}}$

A fundamental manipulation on (1) and (2) results in:

$$
\begin{aligned}
& \frac{d \boldsymbol{i}_{s}^{s}}{d t}=\boldsymbol{A}_{1} i_{s}^{s}+\boldsymbol{B}_{1} \boldsymbol{u}_{s}^{s}+\boldsymbol{P} \Psi_{r m}^{s} \\
& \frac{d \Psi_{r m}^{s}}{d t}=\boldsymbol{A}_{2} \Psi_{r m}^{s}+\boldsymbol{B}_{2} \boldsymbol{i}_{s}^{s}
\end{aligned}
$$

with

$\boldsymbol{A}_{1}=\left[\begin{array}{cc}-\left(\frac{1}{\delta T_{s}}+\frac{1-\delta}{\delta T_{r}}\right) & 0 \\ 0 & -\left(\frac{1}{\delta T_{s}}+\frac{1-\delta}{\delta T_{r}}\right)\end{array}\right], \boldsymbol{B}_{1}=\left[\begin{array}{cc}\frac{1}{\delta L_{s}} & 0 \\ 0 & \frac{1}{\delta L_{s}}\end{array}\right], \boldsymbol{P}=\left[\begin{array}{cc}\frac{1-\delta}{\delta T_{r}} & \frac{(1-\delta) \omega}{\delta} \\ -\frac{(1-\delta) \omega}{\delta} & \frac{1-\delta}{\delta T_{r}}\end{array}\right], \boldsymbol{A}_{2}=\left[\begin{array}{cc}-\frac{1}{T_{r}} & -\omega \\ \omega & -\frac{1}{T_{r}}\end{array}\right], \boldsymbol{B}_{2}=\left[\begin{array}{cc}\frac{1}{T_{r}} & 0 \\ 0 & \frac{1}{T_{r}}\end{array}\right]$

For MPC control design, the continuous-time model (10) needs to be transformed into discrete-time model with sampling period $\mathrm{T}_{\mathrm{s}}$ by using forward-Euler method as following:

$$
\begin{aligned}
& \boldsymbol{i}_{s, k+1}^{s}=\boldsymbol{\Phi}_{1} \boldsymbol{i}_{s, k}^{s}+\Gamma_{1} \boldsymbol{u}_{s, k}^{s}+\boldsymbol{D}_{k} \Psi_{r m, k}^{s} \\
& \Psi_{r m, k+1}^{s}=\boldsymbol{\Phi}_{2} \boldsymbol{\Psi}_{r m, k}^{s}+\Gamma_{2} \boldsymbol{i}_{s, k}^{s}
\end{aligned}
$$

in which

$$
\begin{aligned}
& \Phi_{1}=\boldsymbol{I}_{2}+T_{s} \boldsymbol{A}_{1} ; \boldsymbol{\Phi}_{2}=\boldsymbol{I}_{2}+T_{s} \boldsymbol{A}_{2} ; \Gamma_{1}=T_{s} \boldsymbol{B}_{1} ; \\
& \boldsymbol{\Gamma}_{2}=T_{s} \boldsymbol{B}_{2} ; \boldsymbol{D}_{k}=T_{s} \boldsymbol{P} ; \boldsymbol{I}_{2}=\left[\begin{array}{ll}
1 & 0 \\
0 & 1
\end{array}\right]
\end{aligned}
$$

Based on (11), the predictive current in $\mathrm{N}$ step ahead can be computed by:

$$
\left[\begin{array}{c}
\boldsymbol{i}_{s, k+1}^{s} \\
\boldsymbol{i}_{s, k+2}^{s} \\
\ldots \\
\boldsymbol{i}_{s, k+N}^{s}
\end{array}\right]=\left[\begin{array}{cccc}
\boldsymbol{\Gamma}_{1} & 0 & \ldots & 0 \\
\boldsymbol{\Phi}_{1} \Gamma_{1} & \Gamma_{1} & \ldots & 0 \\
\vdots & \vdots & \ddots & \vdots \\
\boldsymbol{\Phi}_{1}^{N-1} \Gamma_{1} & \boldsymbol{\Phi}_{1}^{N-2} \Gamma_{1} & \ldots & \Gamma_{1}
\end{array}\right]\left[\begin{array}{c}
\boldsymbol{u}_{s, k+1}^{s} \\
\boldsymbol{u}_{s, k+2}^{s} \\
\ldots \\
\boldsymbol{u}_{s, k+N}^{s}
\end{array}\right]+\left[\begin{array}{c}
\boldsymbol{\Phi}_{1} \\
\boldsymbol{\Phi}_{1}^{2} \\
\vdots \\
\boldsymbol{\Phi}_{1}^{N}
\end{array}\right] \boldsymbol{i}_{s, k}^{s}+\left[\begin{array}{cccc}
\boldsymbol{D}_{k} & 0 & \ldots & 0 \\
\boldsymbol{\Phi}_{1} \boldsymbol{D}_{k} & \boldsymbol{D}_{k} & \ldots & 0 \\
\vdots & \vdots & \ddots & \vdots \\
\boldsymbol{\Phi}_{1}^{N-1} \boldsymbol{D}_{k} & \boldsymbol{\Phi}_{1}^{N-2} \boldsymbol{D}_{k+1} & \ldots & \boldsymbol{D}_{k+N-1}
\end{array}\right]\left[\begin{array}{c}
\boldsymbol{\Psi}_{r m, k}^{s} \\
\boldsymbol{\Psi}_{r m, k+1}^{s} \\
\ldots \\
\boldsymbol{\Psi}_{r m, k+N-1}^{s}
\end{array}\right]
$$

\section{CONTROL DESIGN}

\subsection{FCS-MPC design}

The block diagram of the IM control system is shown in Figure 3(a) which conists of two outer loops including a speed regulator, a flux regulator and an inner current loop using FCS-MPC. The two outer loops designed in synchronous reference frame $d q$ generate the reference stator currents. Then, these reference currents are transformed into $\alpha \beta$ coordinate and used for the FCS-MPC design. Based on the IM 
model, the optimal voltage vector is chosen to minimize a cost function in which one or several objectives may be considered such as: minimal tracking error, capacitor volage balance, minimal switching loss, etc. The detail FCS-MPC algorithm which is activated in every consecutive sampling period is shown in Figure 3(b), in details.

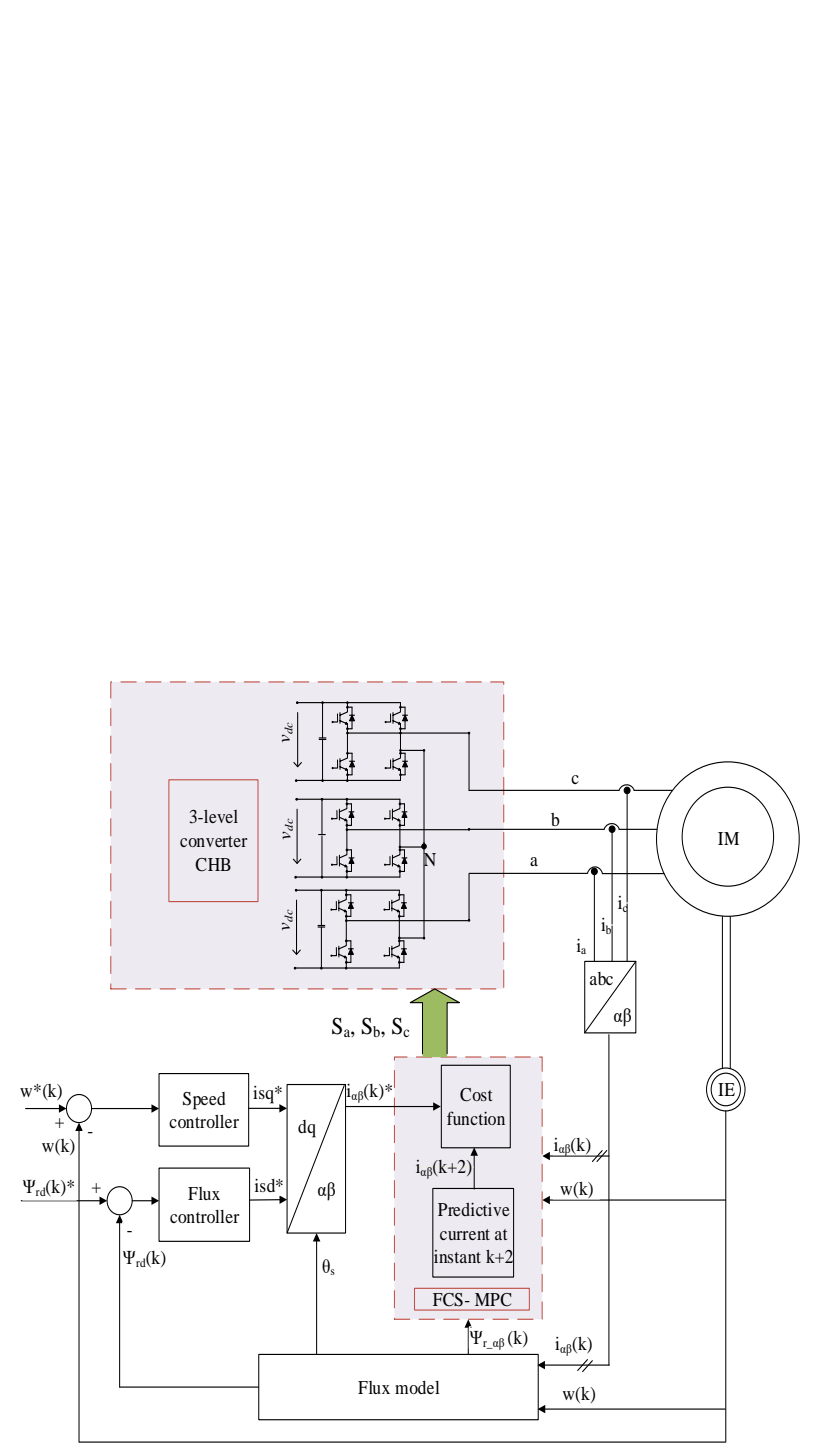

(a)



(b)

Figure 3. FCS control strategy, (a) IM control scheme, (b) Predictive current control algorithm

\subsection{Cost function selection}

In this research, the cost function is chosen based on the predictive current error in $\alpha \beta$ coordinate of the induction motor.

\subsubsection{Formulation of the current error}

The error between the predictive current and its reference can be expressed as an absoltute value, square value or integral value [3]. If only the present tracking error is used by the cost function, absolute error and square error give same performance. When the present and past values of the tracking error are considered, the square of error gives better tracking performance than the absolute error while the integral of error gives the best performance. However, a cost function with integral of tracking error also requires higher computational cost. 


\subsubsection{Delay compensation}

In the ideal case, the time needed for calculation is negligible. Assume that the currents are measured at time instance $t_{k}$, the optimal voltage vector that minimizes the error at time instance $t_{k+1}$ is chosen and applied immediately at $t_{k}$. Therefore, the load current tracks the predicted current at $t_{k+1}$. However, if the calculation time is significant compared to the sampling time, there is a delay between the measured current insant and the applied new voltage vector instant. During the delay time, the previous voltage vector is still applied, which makes the load current move away from the reference and increases the current ripple. A simple solution to compensate this delay is to take the calculation time into account and apply the selected voltage vector after the next sampling instant $[3,14,16]$. The load current reaches the predicted value at $t_{k+2}$.

\subsubsection{Prediction of future references}

In general, the future references are unknown and needed to be estimated by using a second-order extrapolation [10]. However, for sufficiently small sampling time, the future reference value at time $t_{k+2}$ is assumed to be approximately equal to the present reference value at time $t_{\mathrm{k}}[3]: i_{\alpha \beta}^{*}(k) \approx i_{\alpha \beta}^{*}(k+2)$. Based on the aforementioned analysis, the cost function is chosen as:

$$
J=\left|\boldsymbol{i}_{\alpha}^{*}(k)-\boldsymbol{i}_{\alpha}(k+2)\right|+\left|\boldsymbol{i}_{\beta}^{*}(k)-\boldsymbol{i}_{\beta}(k+2)\right|
$$

$i_{\alpha \beta}^{*}(k)$ : Reference stator current of the motor in $\alpha \beta$ coordinate at time instance $t_{\mathrm{k}}$.

$i_{\alpha \beta}(k+2)$ : Predictive stator current of the motor in $\alpha \beta$ coordinate at time instance $t_{\mathrm{k}+2}$.

\section{FPGA IMPLEMENTATION}

\subsection{Functional internal circuit (IC) design.}

A complicated algorithm can be divided into many smaller calculation steps and an internal circuit needs to be designed and programed functionaly to perform each step. An IC includes two fundamental blocks: a finite state machine (FSM) and a processing unit (PU) as shown in Figure 4(a). The FSM block contains all finite states of the IC and control signals to processing unit. Meanly or Moore method are usually used to design the FSM with several typical signals: $c l k$, rst, init and done. In which, $C l k$ and $r s t$ are operating clock and reset signal for the circuit, respectively. Init and done signal is set to ' 1 ' for only one clock period when the IC starts and finishes its operation. The done signal is connected to the init signal of the other circuit so that sequential calculation can be implemented. Since an internal circuit only operates in a fixed small time and is inactive most of the time, this design avoids the propagation of unespected glitches and reduces the FPGA power consumption. The PU block contains operators +, -, x, / and takes Data_in as input data to calculate and then send the results to the Data_out under the control of the FSM. The structure of the PU is designed by the pipelined structure as shown in Figure 4(b) to synchronize the data and signals. c. Predictive current control implementation based on FPGA platform.

The flow chart shown in Figure 5(a) illustrates how to implement the FCS-MPC for current loop of the IM on a FPGA platform. To solve the algorithm described in the previous section, there are nine steps corresponding to nine internal circuits. The name of Stepl to Step 9 are: $A D C \_r e a d, a b c \_t o \_\alpha \beta, D q \_$to_ $\alpha \beta$, $I s \_t o \_f l u x, P r e \_m o d e l, J \_c a l c$ circuit, Find_mindJ, $\alpha \beta \_t o \_d q$ and Flux_model, respectively. Since Step2 requires the data calculated in Stepl while Step3 requires the data from Step2, the operation of circuits 1,2,3 is sequential. Similarly, the circuits 3,5,6,7 and 8,9 must run sequentially. Meanwhile, Step5 requires the data from both Step3 and Step4, so that circuit 3 and 4 must operate in parallel. Because circuit 4 needs more calculation time than circuit 3 , circuit 5 only take the input data when circuit 4 ends its operation, which means the done signal of circuit 4 is the init signal of circuit 5 . On the other hand, Step 9 only requires data from Step 8 which means circuit 8 and 9 operate in parallel with circuit 3,5,6,7. Finally, the execution time of the FCS-MPC is shown in Figure 5b. As can be observed, several steps can be carried out in parallel which reduces the computational time of the implemented algorithm. The parallel computation ability of the FPGA, which is not available in conventional DSP/microcontroller, allows the MPC to be applied to many other fields without having to worry about the computational time. 


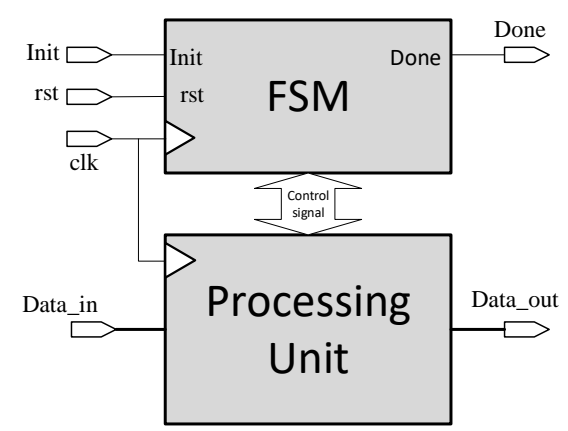

(a)
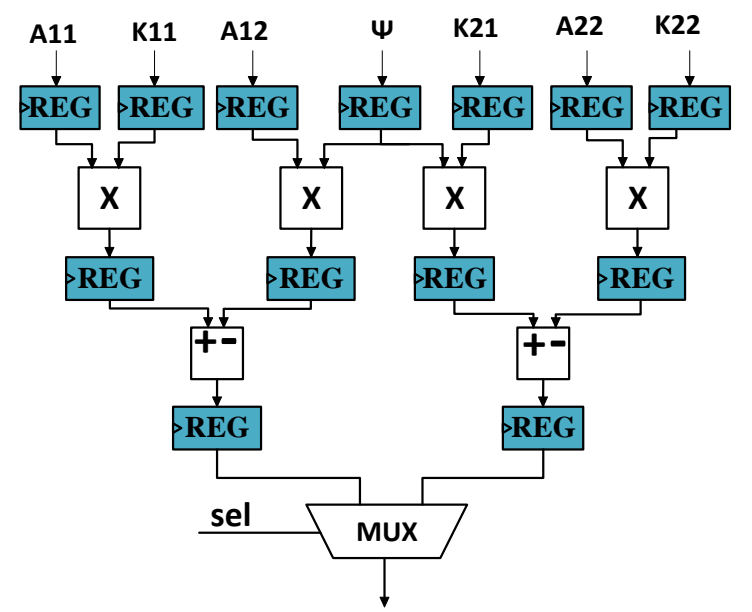

(b)

Figure 4. Functional, (a) IC structure, (b) Pipelined structure

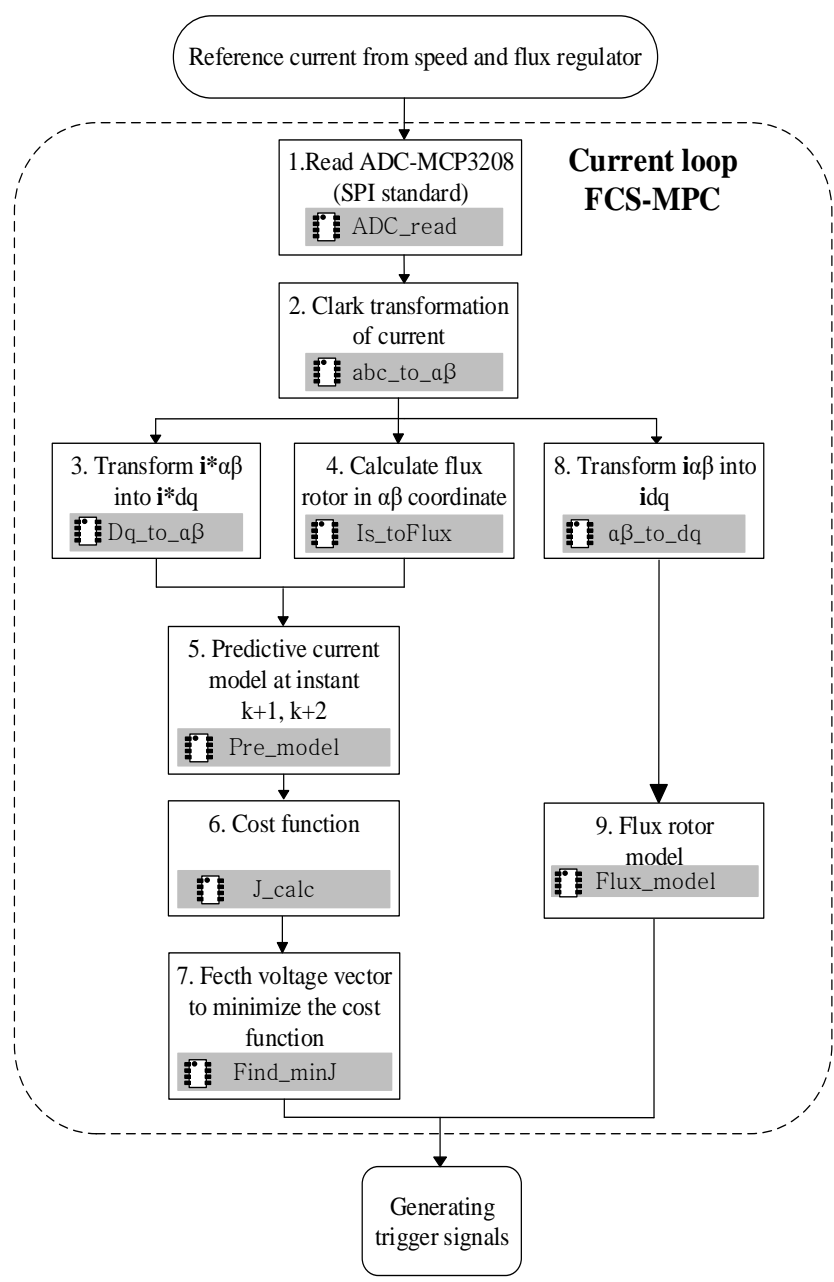

(a)

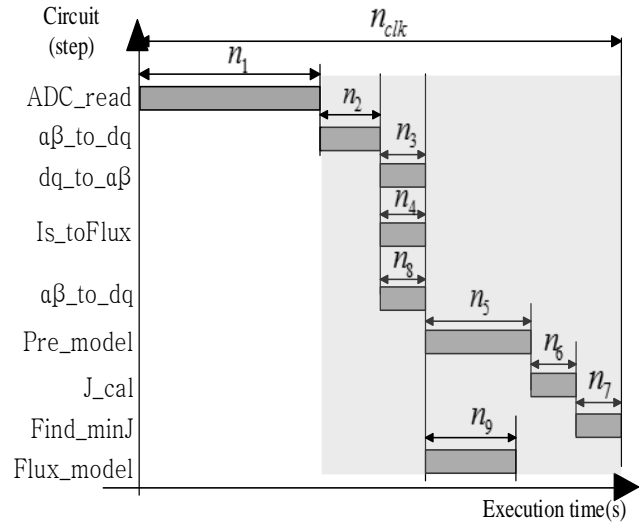

(b)

Figure 5. Flowchart, (a) FPGA implementation (b) IC's execution time 


\subsection{HIL-FPGA platform}

To quickly verify the FCS-MPC for IM without risky experiments, real-time simulation based on HIL platform are conducted. The virtual IM motor with parameters provided in Table 1 and the 3-level CHB inverter are simulted by Typhoon HIL 402 device. The control algorithm is implemented by a FPGA card named ZYBO-27. The block diagram and the experimental devices of the real-time simulation system are shown in Figure 6 and Figure 7, respectively.

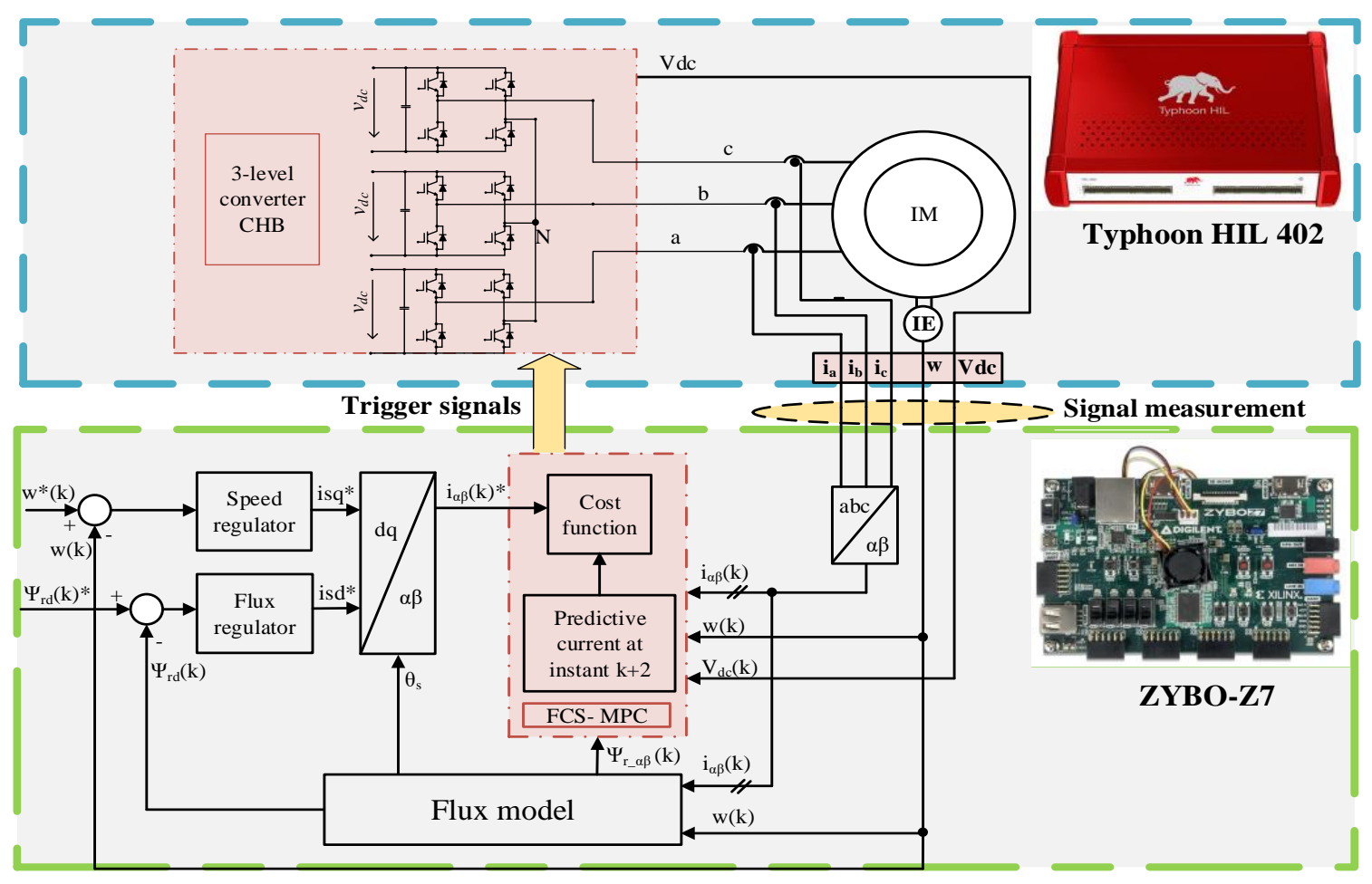

Figure 6. Block diagram of the HIL-based simulation system

Table 1. Parameters of the IM

\begin{tabular}{llc}
\hline Symbol & \multicolumn{1}{c}{ Quantity } & Value \\
\hline $\mathrm{P}_{\text {rate }}$ & Rate power & $2.2 \mathrm{~kW}$ \\
$\mathrm{~T}_{\text {rate }}$ & Rate torque & $7.3 \mathrm{Nm}$ \\
$\mathrm{I}_{\text {rate }}$ & Rate phase current & $4.7 \mathrm{~A}$ \\
$\mathrm{~V}_{\text {rate }}$ & Rate phase voltage & $400 \mathrm{~V}$ \\
$\mathrm{f}_{\text {rate }}$ & Rate frequency & $50 \mathrm{~Hz}$ \\
$\mathrm{~N}_{\text {rate }}$ & Rate speed & $2880 \mathrm{rpm}$ \\
$\mathrm{R}_{\mathrm{s}}$ & Stator resistance & $1.99 \Omega$ \\
$\mathrm{R}_{\mathrm{r}}$ & Rotor resistance & $1.84 \Omega$ \\
$\mathrm{L}_{\mathrm{m}}$ & Mutual inductance & $0.37 \mathrm{mH}$ \\
\hline
\end{tabular}

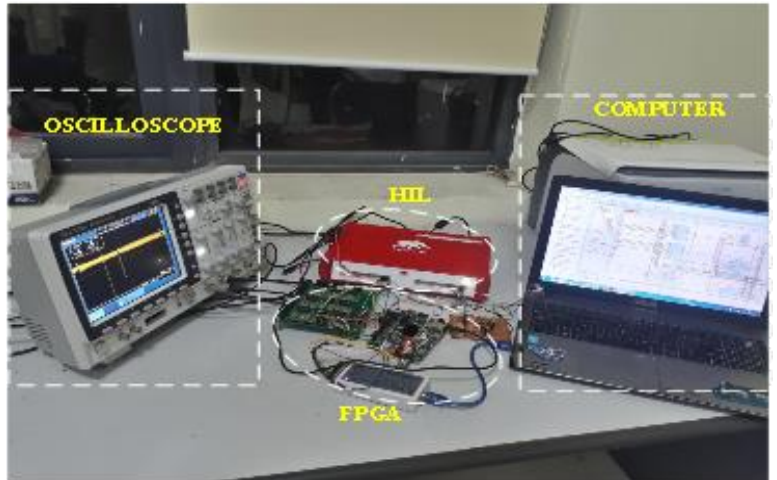

Figure 7. Experiment devices

\section{RESULTS AND DISCUSSION}

In this section, various real-time simulations are carried out to verify the developed FCS-MPC applied to IM control. First, the transient response of the control system with the load disturbance is tested. At time instance $t=\{0.05 \mathrm{~s}, 0.5 \mathrm{~s}, 0.75 \mathrm{~s}\}$, the load torque is suddenly changed with corresponding values $T_{L}=\left\{0,0.5 T_{\text {rate }}, T_{\text {rate }}\right\}$ while the reference speed is fixed at $\omega_{\text {ref }}=300\left(\mathrm{rad} \mathrm{s}^{-1}\right)$. As can be observed in Figure 8 , the electromagnetic torque generated by the IM quickly tracks the load torque to maintain the rotor 
speed at its desired value. From time instance $t=1.5 \mathrm{~s}$, speed reveral of the IM with constant load is investigated. The reference speed is changed at time instance $t=1.5 \mathrm{~s}$ and $t=4.3 \mathrm{~s}$ with corresponding values $N_{\text {ref }=-} N_{\text {rate }}$ and $N_{\text {ref }} O$. In this case, the rotor speed also quickly trackes its reference with negligible tracking error, i.e., about $0.2 \mathrm{rad} / \mathrm{s}$. In the second scenario, the ability to generate electromagnetic torque at standstill of the IM control system is clarified. With employed FCS-MPC for the current loop, the generated electromagnetic torque quickly tracks the load torque at zero speed in just $3 m s$ as shown in Figure 9. This quick response is sufficient for most practical applications and comparable to the well-known direct torque control (DTC).
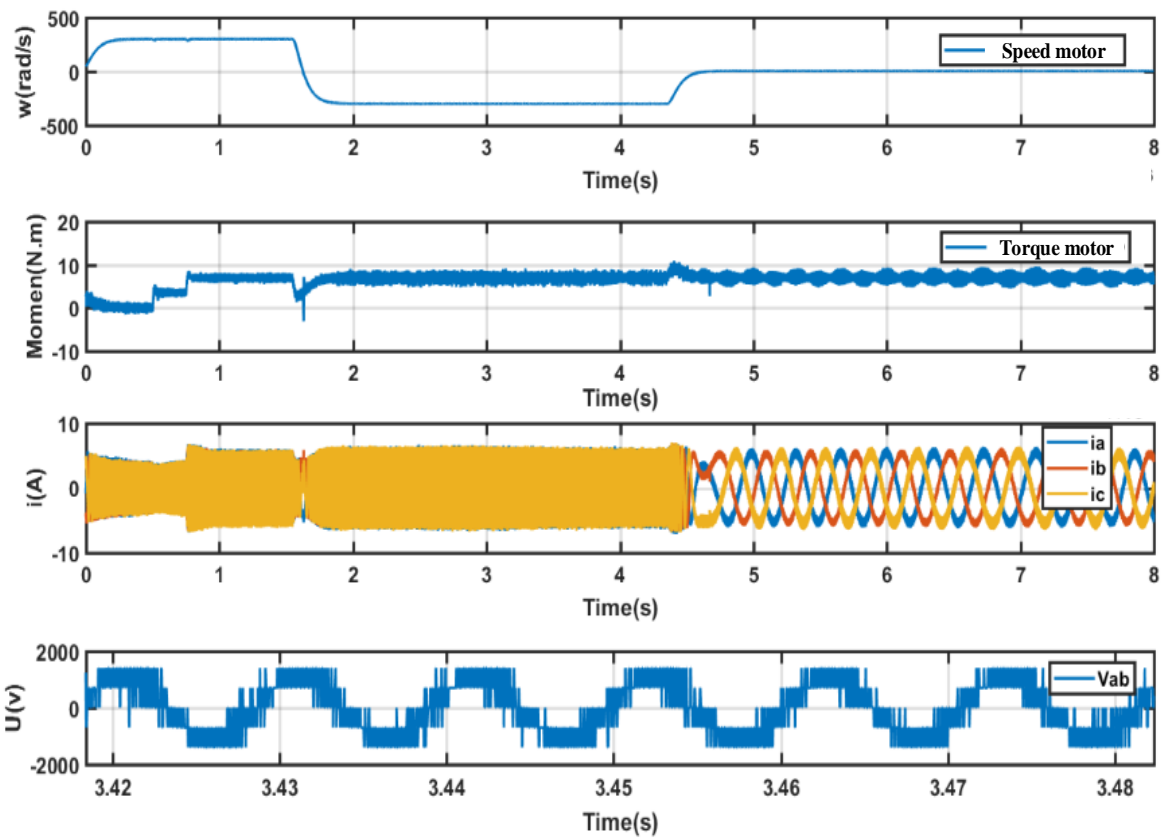

(a)
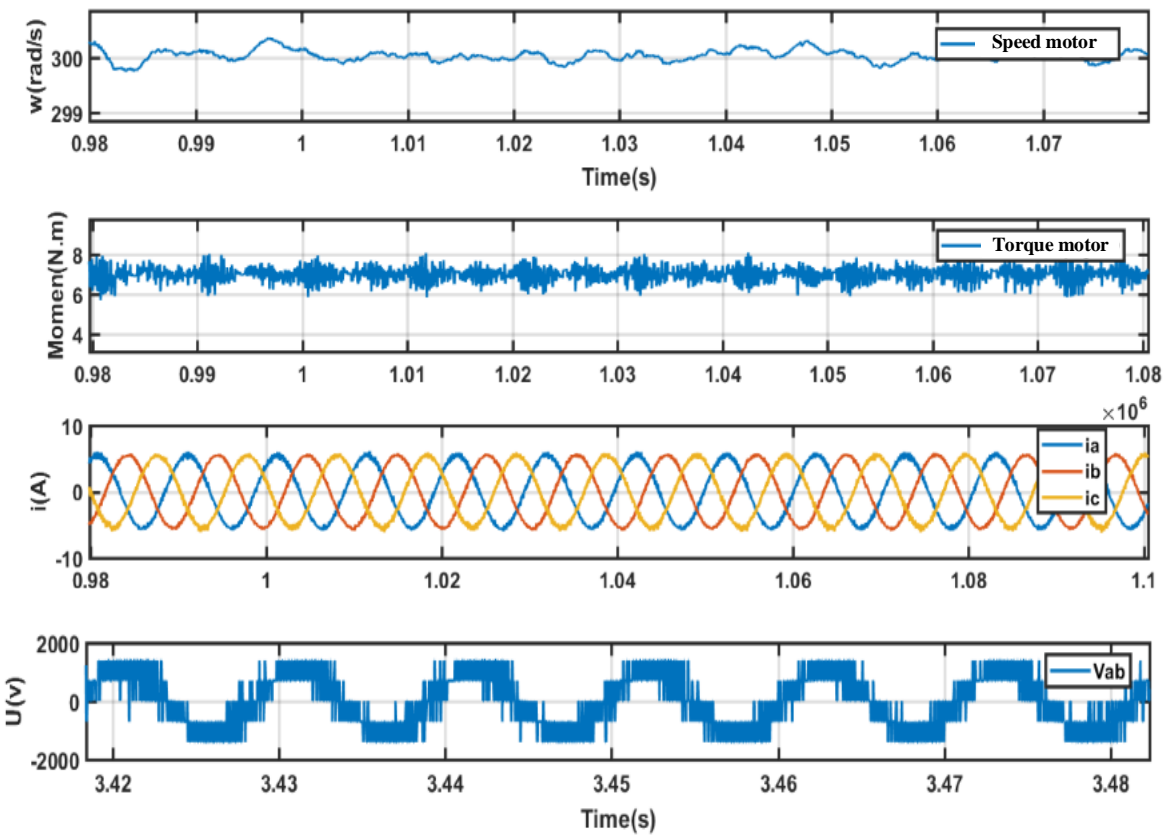

(b)

Figure 8. Electromagnetic torque, (a) Time-varying speed motor and load torque, (b) Zoom-in result 



(a)

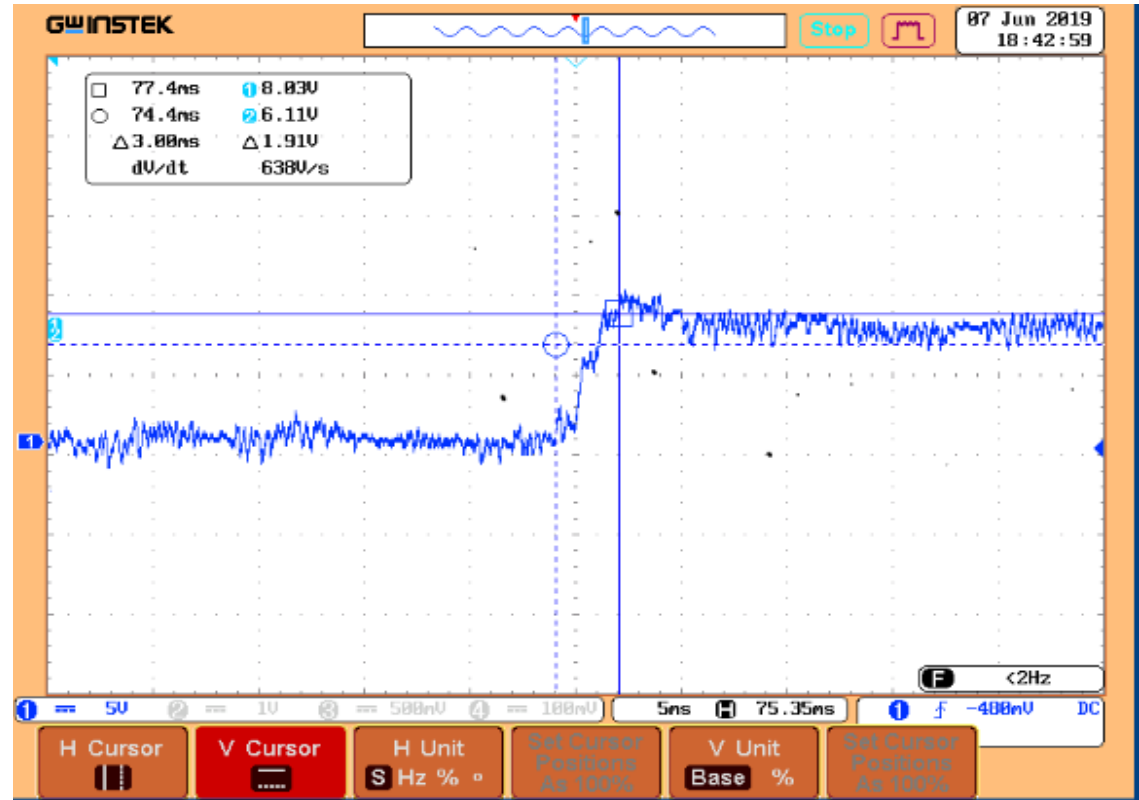

(b)

Figure 9. Generated torque, (a) Load torque and load current at standstill, (b) Torque step response

\section{CONCLUSION}

In this paper, an advanced solution to quickly develop the FCS-MPC for IM fed by multilevel CHB inverter is discussed. First, the behavior of the stator current in future is predicted with each of possible voltage vector based on the explicit discrete-time mathematical model of the IM. The optimal voltage vector which fulfill the objective of a predefined cost function is selected and applied to the CHB inverter. Second, the FPGA with parallel calculation ability is used to minimize the computational time of the complicated control algorithm like MPC. Finally, to eliminate the burden of time on hardware design as well as to avoid potential risks with high power experimental systems, real-time simulations with high-fidelity mathematical models implemented by HIL platform are conducted to verify the control algorithm. Achieved real-time simulations show that the developed FCS-MPC gives good performance not only in steady-state but also in transient-state. 


\section{ACKNOWLEDGEMENTS}

This research is sponsored by Hanoi University of Science and Technology (HUST) under project number T2018-PC-050. We would like to thank our colleagues from school of electrical engineering who provide insight and expertise that greatly assist the research.

\section{REFERENCES}

[1] M. P. Kazmierkowski and L. Malesani, "Current control techniques for three-phase voltage-source PWM converters: a survey," in IEEE Transactions on Industrial Electronics, vol. 45, no. 5, pp. 691-703, Oct. 1998.

[2] Tobias Geyer, "Model Predictive Control of High-Power Converters and Industrial Drives," 2016.

[3] Jose Rodriguez, Patricio Cortes, "Predictive control of power converters and electrical drives," Wiley-IEEE Press, 2012.

[4] Liuping Wang, Shan Chai, Dae Yoo, Lu Gan, Ki Ng, "PID and Predictive control of electrical drives and power converters using Matlab/ Simulink," Wiley-IEEE Press, 2015.

[5] Yongchang Zhang, Bo Xia, Haitao Yang, Jose Rodriguez "Overview of Model Predictive Control for Induction motor drives", Chinese Journal of Electrical Engineering, vol. 2, no. 1. pp. 62-76, 2019.

[6] H. Gao, B. Wu, D. Xu, M. Pande and R. P. Aguilera, "Common Mode Voltage Reduced Model Predictive Control Scheme for Current Source Converter-Fed Induction Motor Drives," IEEE Transactions on Power Electronics, vol. 32, no. 6, pp. 4891-4904, 2017.

[7] P. Cortes et al., "Guidelines for weighting factors design in Model Predictive Control of power converters and drives," 2009 IEEE International Conference on Industrial Technology, Gippsland, VIC, pp. 1-7, 2009.

[8] S. Kouro, P. Cortes, R. Vargas, U. Ammann and J. Rodriguez, "Model Predictive Control-A Simple and Powerful Method to Control Power Converters," IEEE Transactions on Industrial Electronics, vol. 56, no. 6, pp. 1826-1838, 2009

[9] P. Cortés, A. Wilson, S. Kouro, J. Rodriguez and H. Abu-Rub, "Model Predictive Control of Multilevel Cascaded H-Bridge Inverters," IEEE Transactions on Industrial Electronics, vol. 57, no. 8, pp. 2691-2699, 2010.

[10] J. Rodriguez et al., "Predictive Current Control of a Voltage Source Inverter," IEEE Transactions on Industrial Electronics, vol. 54, no. 1, pp. 495-503, 2007.

[11] M. A. Hosseinzadeh, M. Sarbanzadeh, E. Sarbanzadeh, M. Rivera and P. Wheeler, "Predictive Control Applied to a Cascaded H-Bridge Multilevel Converter," 2018 IEEE International Conference on Electrical Systems for Aircraft, Railway, Ship Propulsion and Road Vehicles \& International Transportation Electrification Conference (ESARSITEC), Nottingham, pp. 1-6, 2018.

[12] Goh, H H; Azuwien Aida; Lee, S S; Sim, SY; Goh, K C. "Predictive Direct Power Control (PDPC) of Gridconnected Dual-active Bridge Multilevel Inverter (DABMI)," International Journal of Power Electronics and Drive Systems (IJPEDS), vol. 8, no. 4, pp. 1524-1533. 2017.

[13] Abbasi, Muhammad \& Husain, Abdul \& Al-qaraghuli, Hasan. "Modular Approach to Implement Model Predictive Control on Three Phase Voltage Source Inverter". International Journal of Power Electronics and Drive Systems (IJPEDS), vol. 9, no 897, pp. 897-904, 2018.

[14] P. Cortes, J. Rodriguez, C. Silva and A. Flores, "Delay Compensation in Model Predictive Current Control of a Three-Phase Inverter," in IEEE Transactions on Industrial Electronics, vol. 59, no. 2, pp. 1323-1325, 2012

[15] Yusoff, Siti Hajar and Midi, Nur Shahida and Khan, Sheroz and Tohtayong, Majdee "Predictive control of AC/AC matrix converter," International Journal of Power Electronics and Drive System (IJPEDS), vol. 8, no. 4. pp. 1932-1942, 2017.

[16] M. Uddin, S. Mekhilef, M. Nakaoka and M. Rivera, "Model predictive control of induction motor with delay time compensation: An experimental assessment," 2015 IEEE Applied Power Electronics Conference and Exposition (APEC), Charlotte, NC, pp. 543-548, 2015.

[17] V. C. Mai, M. L. Nguyen, T. H. Vo, P. V. Hoang and T. M. Tran, "Hardware In the Loop Simulation of Predictive Current Control for IM Fed by Multi-Level Cascaded H-Bridge Inverters," 2019 IEEE Vehicle Power and Propulsion Conference (VPPC), Hanoi, Vietnam, pp. 1-5, 2019.

[18] Q. Meng, J. Li, H. Li and Y. Yan, "Model predictive control of induction motors based on improved discretizing method under low switching frequency," IECON 2017 -43rd Annual Conference of the IEEE Industrial Electronics Society, Beijing, pp. 5144-5149, 2017.

[19] Y. Zhang and H. Yang, "Generalized Two-Vector-Based Model-Predictive Torque Control of Induction Motor Drives," IEEE Transactions on Power Electronics, vol. 30, no. 7, pp. 3818-3829, 2015.

[20] Wu, Cascaded H-Bridge Multilevel Inverters 7.1, "High-Power Converters and AC Drives", pp. 119-142, 2006.

[21] M. Marchesoni, M. Mazzucchelli, and S. Tenconi, "A Nonconventional Power Converter for Plasma Stabilization", IEEE Transactions on Power Electronics, vol. 5, no. 2. pp. 212-219, 1990.

[22] B. Hemanth Kumar, M. M. Lokhande, R. R. Karasani, and V. B. Borghate, "Fault tolerant operation of CHB multilevel inverters based on the SVM technique using an auxiliary unit", Journal of Power Electronics, vol. 18, no. 1. pp. $56-69,2018$.

[23] C. M. Van, T. N. Xuan, P. V. Hoang, M. T. Trong, S. P. Cong, and L. N. Van, "A Generalized space vector modulation for cascaded h-bridge multi-level inverter", Proceedings of 2019 International Conference on System Science and Engineering, ICSSE 2019, pp. 18-24, 2019.

[24] C. Buccella, C. Cecati, and H. Latafat, "Digital control of power converters", x2014, a survey, Industrial Informatics, IEEE Transactions on, vol. 8, no. 3, pp. 437-447, 2012 
[25] M. Perez, M. Vasquez, J. Rodriguez, and J. Pontt, " FPGA-based predictive current control of a three-phase active front end rectifier", in Industrial Technology, 2009. ICIT 2009. IEEE International Conference on, pp. 1-6, 2009.

[26] J. Alvarez, Ó. Lopez, F. D. Freijedo and J. Doval-Gandoy, "Digital Parameterizable VHDL Module for Multilevel Multiphase Space Vector PWM", IEEE Transactions on Industrial Electronics, vol. 58, no. 9, pp. 3946-3957, 2011

\section{BIOGRAPHIES OF AUTHORS}
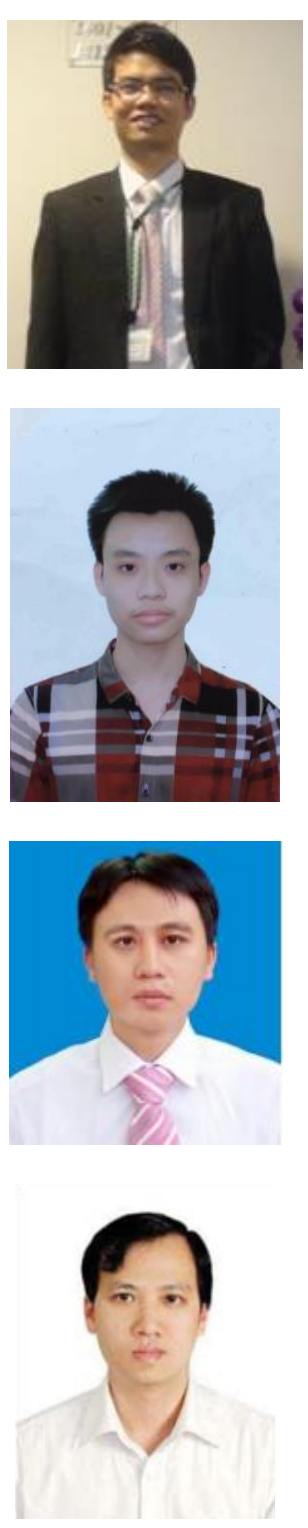

Mai Van Chung received his M.S degree from Hanoi University of Science and Technology, Vietnam in 2016 in Control Engineering and Automation. Since 2017, he has started to study his $\mathrm{PhD}$ degree at Hanoi University of Science and Technology. His research interests include Multilevel converter, electrical machine drive..

Tuan Anh Do received his B.S degree from Hanoi University of Science and Technology, Vietnam in 2019 in Control Engineering and Automation. Since 2019, he has started to study his M.S degree at Hanoi University of Science and Technology. His research interests include power electronics converters for apllications such as photovoltaic, battery and electrical machine drive.

Phuong Vu received his B.S., M.S., and Ph.D. degrees from Hanoi University of Science and Technology, Vietnam, in 2006, 2008, and 2014, respectively, all in Control Engineering and Automation. Since 2006 he has been employed at Hanoi University of Science and Technology, where he is a lecturer and researcher at school of electrical engineering. His research interests include modeling and controlling of power electronics converters for applications such as photovoltaic, wind system, electrical machine drive.

Nguyen Manh Linh received his B.S. and M.S. degrees in electrical engineering from Hanoi University of Science and Technology, Hanoi, Vietnam, in 2008 and 2011, respectively, and the Ph.D. degree from Graduate School of Engineering and Science in Shibaura Institute of Technology, Tokyo, Japan in 2018. He is currently working as a lecturer in the Department of Industrial Automation, School of Electrical Engineering, Hanoi University of Science and Technology, Hanoi, Vietnam. His research interests include model predictive control, sliding mode control, disturbance observer, advanced control theory and its applications to micro/nano positioning systems, digital control design for power electronic converters. 